\title{
XVII. On the unequal decomposition of electrolytes, and the theory of electrolysis
}

\section{Mr. James Napier}

To cite this article: Mr. James Napier (1846) XVII. On the unequal decomposition of electrolytes, and the theory of electrolysis, Philosophical Magazine Series 3, 29:192, 92-99, DOI: $10.1080 / 14786444608645585$

To link to this article: http://dx.doi.org/10.1080/14786444608645585

曲 Published online: 30 Apr 2009.

Submit your article to this journal $\lceil\pi$

ЏII Article views: 2

Q View related articles $\square$ 
XVII. On the unequal Decomposition of Electrolytes, and the Theory of Electrolysis. By Mr. J M Es NApIER*.

I $\mathrm{N}$ a paper which I submitted to the Society last session 1 upon this subject + , it was mentioned that the fundamental law laid down by electro-chemists, "That there can be no inequality of decomposition in any part of an electrolyte," is not applicable under all circumstances, especially when the negative element of the electrolyte can combine with the positive electrode, there being under such circumstances an increased tendency in the electrode to combine with the electrolyte, which causes a greater amount of decomposition or chemical action at the positive than at the negative electrode.

That the extra amount of decomposition at the positive electrode is not the result of the ordinary solvent powers of the electrolyte for the metal composing the electrode, was shown by pieces of the same metal being put into the same solutions as the electrolyte the same length of time as the battery was in action, and which were in some cases not affected, and in others only a small fraction of that which had taken place at the positive electrode above what the current of electricity passing accounted for ; showing that the increased affinity between the elements of the electrolyte and the electrode had its origin in some influence communicated by the battery, and was not accounted for by the amount of electricity passing, measured by the deposition of a metal upon the negative electrode, and as experiments which were being made showed, without any relation to that current.

I had observed, while experimenting upon electrical endosmose, that there seemed some relation between the cause of measurable endosmose and the phænomenon under consideration: it became therefore probable that the element of an electrolyte liberated at the negative pole, such as a deposited metal, might not be, as I had formerly thought, an accurate measure of the whole electricity passing through the solution under all circumstances, but that a feeble current may be also passing, which may be sufficient to give a greater disposition, if I may be allowed the term, to the solid electrode to combine with the elements of the electrolyte, but not of sufficient power to decompose all the particles of the compound fluid through which it passes to the negative electrode, the solution conducting it as a solid conductor would, or rather, as appears from the results described in my paper on

* Communicated by the Chemical Society; having been read January $5,1846$.

+ See Phil. Mag. S. 3. vol. xxvi. p. 211. 
endosmose, the electricity taking the dissolved particles with it to the negative electrode and producing the phænomena of endosmose. These suppositions therefore became the object of an inquiry, which I shall now describe in detail.

I took a piece of amalgamated zinc, measuring 2 by $2 \frac{1}{2}$ inches, in such state of amalgamation that dilute sulphuric acid had no action upon it; this was put into a mixture of sulphuric acid and water in the proportion of 1 acid to 24 water, and surrounded with copper, which was placed as close to the zinc as would allow a free current of the solution between them, as well as the escape of gas, with the view of interrupting as little as possible the free action of the acid upon the zinc. This was kept in action for an hour, when it was found that the zinc had dissolved from it 97 grains. This I assumed as the maximum amount of chemical action which could be obtained between the zinc and acid of this strength, at least under the influence of copper. 'The zinc and copper being again put into this liquil, but with the two metals 1 inch apart, connected by a slip of copper at the surface of the liquid, in one hour there was dissolved from the zinc 56.5 grains. The two metals being again placed in the same position, but connected by two copper electrodes of equal size placed into a solution of sulphate of copper, at the expiration of an hour there was deposited upon the negative electrode 9 grains of copper, and there were dissolved from the zinc 10.7 grains. Taking another zinc and copper and putting them into the acid connected with the first in the manner practised for intensity, there were deposited in one hour 17 grains. The zinc in cell had lost 18 grains. With 4 pairs zinc and copper in acid there were deposited 26 grains, and dissolved from the zinc $27 \cdot 7$ grains. With 6 pairs there were deposited 34 grains, and dissolved from zinc 36 grains; and with 9 pairs there were deposited 43 grains, and dissolved from the zinc 45 grains. And thus it went on increasing in quantity by the addition of plates until the action of the acid and zinc came nearly to the same as was assumed as a maximum, namely, 97 grains; with 30 pairs there were dissolved from zinc 101 grains, with 35 pairs 99 , which I consider very close to the assumed quantity.

Assuming the position which the results of these experiments suggest, I would say, that if the chemical energy induced between the acid and zinc uncler the influence of copper be equal to 100 grains per hour, but by distance or the interposition of a medium of inferior conducting power the chemical action is reduced to 10 grains per hour, the remaining tendency or disposition of the acid and zinc to unite 


\section{Mr. Napier on the unequal Decomposition of Electrolytes,}

will be equal to 90 ; and by increasing the action, either by adding intensity or decreasing the resistance, so that it amounts to 25 grains per hour, we decrease the tendency to further action to 75 , and so on, the one decreasing as the other increases. Now, if this tendency for further action between the acid and zinc be the source of this feeble or undecomposing current, and this the cause of an extra chemical action at the positive over the negative electrode, then the amount of this extra action at this locality will be greatest with a weak battery, at least have some relation to the surface of zinc exposed and the amount of actual chemical action going on. That this is the case the following experiments will show. To save repetition, I may state that when small plates are mentioned the measures of the zinc are 2 by $2 \frac{1}{2}$ inches; when large plates are named they measure 5 by 6 inches.

1. With small plates, the electrodes being the same size as plates, both placed in sulphate of copper with a very little free acid. 'The current passing four hours, the results were as under :-

One pair negative gained 27 grs. Positive lost 30.5 grs.

$\begin{array}{lllllll}\text { Two pairs } & \ldots & 44 & \ldots & \ldots & 49 & \ldots \\ \text { Four pairs } & \ldots & 58 & \ldots & \ldots & 63 & \ldots \\ \text { Six pairs } & \ldots & 70 & \ldots & \ldots & 73 & \ldots \\ \text { Nine pairs } & \ldots & 85 & \ldots & \ldots & 87 & \ldots\end{array}$

Taking these results in equivalent proportion, counting the equivalent of copper 32 , the extra action at positive will be-

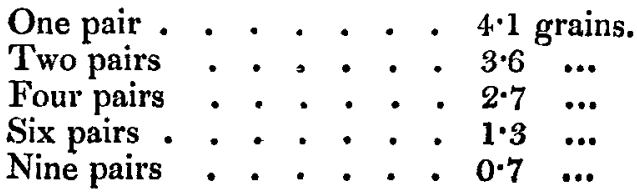

The next experiment was with cyanide of potassium in the proportion of 1 ounce to the pint of water. This was put into one division of a decomposition cell, the other being charged with sulphate of copper; silver positive electrodes were used in the cyanide solution. The battery used was of small plates, the current passing two hours.

One pair negative gained 14 grs, Positive lost 57 grs.

$\begin{array}{lllllll}\text { Two pairs } & \ldots & 14 & \ldots & \ldots & 50 & \ldots \\ \text { Four pairs } & \ldots & 20 & \ldots & \ldots & 70 & \ldots \\ \text { Six pairs } & \ldots & 21 & \ldots & \ldots & 71 & \ldots\end{array}$

The equivalent of deposit being again taken, the proportions of extra solution of positive stand thus:- 


$$
\begin{aligned}
& \text { One pair . . . . . . } 9 \cdot 1 \text { grs. } \\
& \text { Two pairs . . . . . . } 6.8 \text {... } \\
& \text { Four pairs . . . . . } 5 \cdot 7 \text {... } \\
& \text { Six pairs . . . . . . } 0.9 \text {... }
\end{aligned}
$$

I now took a strong solution of cyanide of potassium and divided it into three equal parts : into two were placed porous vessels filled with sulphate of copper, in which were put the negative electrode of the battery, one connected with 9 pairs of small plates, the other with 1 pair of large plates. The same sort of electrodes were used in both experiments. The third portion of cyanide of potassium solution had a piece of copper placed in it of the same size with the electrodes. The battery current was continued one hour. The results were-

9 pairs deposited 12 grains, dissolved 15 grains; equivalent 8 grains.

1 pair deposited 4 grains, dissolved 7 grains; equivalent 24. grains.

Piece of metal in cyanide potassium lost 1.2 grain.

Similar experiments were made with various electrolytes in the positive division, using sulphate of copper in all cases in the negative, the amount deposited being taken as the measure of the decomposing current.

1st. Positive cell charged with a weak solution of cyanide of potassium.

1 pair deposited 7 grains, dissolved 10 grains ; equivalent proportion 13.7 grains.

9 pairs deposited 26 grains, dissolved 31 grains; equivalent proportion $6 \cdot 1$ grains.

2nd. Muriatic acid 1 to 24 water in positive solution.

1 pair deposited 15 grains, dissolved 23 grains; equivalent 17 grains.

9 pairs deposited 54 grains, dissolved 69 grains; equivalent 8.8 grains.

3rd. Positive solution, nitric acid 1 to 24 water.

1 pair deposited 17 grains, dissolved 20 grains; equivalent $5 \cdot 6$ grains.

9 pairs deposited 26 grains, dissolved 29 grains ; equivalent $3 \cdot 7$ grains.

4th. Positive solution, sulphuric acid 1 to 24 water.

1 pair deposiced 20 grains, dissolved 23 grains; equivalent $4 \cdot 3$ grains.

9 pairs deposited 49 grains, dissolved 55 grains; equivalent 3.9 grains.

The next series of experiments are of the same kind, using 


\section{$96 \mathrm{Mr}$. Napier on the unequal Decomposition of Electrolytes,}

1 and 2 pairs of large and small plates; but two porous vessels were used, put into a vessel charged with the same liquid as the positive, the negative in this, as in the last, being charged with sulphate of copper, the electrodes being 2 by $2 \frac{1}{2}$ inches in all the experiments.

1st. Positive solution, sulphuric acid 1 to 24 water.

1 pair small plates deposited 9 grains, dissolved 11 grains; equivalent 7 grains.

1 pair large plates deposited 9 grains, dissolved 12 grains; equivalent $10 \cdot 6$ grains.

2 pairs small plates deposited 16 grains, dissolved 18 grains; equivalent 4 grains.

2 pairs large plates deposited 19 grains, dissolved 22 grains; equivalent 5 grains.

2nd. Positive solution, muriatic acid 1 to 24, water.

1 pair small plates deposited 5 grains, dissolved 6 grains; equivalent 6.3 grains.

1 pair large plates deposited 7 grains, dissolved 9 grains; equivalent $9 \cdot 1$ grains.

2 pairs small plates deposited 9 grains, dissolved 12 grains; equivalent $9 \cdot 4$ grains.

2 pairs large plates deposited 11 grains, dissolved 16 grains; equivalent $14 \cdot 5$ grains.

3rd. Positive solution, nitric acid 1 to 24 water.

1 pair small plates deposited 8 grains, dissolved 9 grains; equivalent 4 grains.

1 pair large plates deposited 8 grains, dissolved 10 grains; equivalent 8 grains.

2 pairs small plates deposited 14 grains, dissolved 15 grains; equivalent $2 \cdot 3$ grains.

2 pairs large plates deposited 19 grains, dissolved 21 grains; equivalent $3 \cdot 3$ grains.

I now took three separate pairs of small plates excited by 1 sulphuric acid to 24 water, and to each attached copper electrodes, which were placed in a solution of sulphate of copper : the electrodes of one were one-half size of the battery plates, of the other equal size, and of the third twice the size of the battery plates. The current passed sixteen hours, the results were as follows :-

Small negative electrode gained $25 \cdot 4$ grains, positive lost $29 \cdot 3$ grains; equivalent $4 \cdot 9$ grains.

Equal-sized negative electrode gained 33 grains, positive lost 37 grains; equivalent 3.8 grains. 
Large negative electrode gained 42 grains, positive lost 4.4 grains; equivalent 1.5 grain.

A piece of zinc and copper, each measuring 3 inches by 3 , were placed in distilled water, and two small electrodes, 1 by 2 inches, attached and placed in a solution of sulphate of copper. The current passing was sufficient to deflect a delicate galvanometer needle $3^{\circ}$ : the current was allowed to pass seventytwo hours. The electrodes being again weighed, the negative had undergone no change, the positive had lost $2 \cdot 6$ grains.

Another experiment of the same kind, but the electrodes placed in dilute sulphuric acid, 1 to 100 water, the current passed forty-eight hours; the negative electrode was found unchanged, the positive had lost 2 grains. A piece of copper suspended in the acid solution during the same time remained unchanged.

These experiments, which are only a few of a great many that were made, all bearing more or less on the point, I think sufficiently prove the view taken both of the origin of the undecomposing current of electricity, and also that it is that current which produces the phænomenon under discussion; namely, a disposition in the positive electrode and in the zinc in the battery to combine with the negative element of the electrolyte up to a given point, varying according to the strength of acid, and the negative properties, if we may so term it, of the metal in contact with the zinc, through the influence of which the chemical action is induced.

The results of the experiments of this as well as my preceding paper upon electrical endosmose, are applicable to the explanation of various natural and chemical phænomena, the investigations into some of which $I$ am at present engaged with. At present I shall confine myself to a few remarks upon the philosophy of electrolytic action which these experiments suggest.

The manner in which electricity passes through and decomposes solutions, is a subject that has occupied the attention of electro-chemists since its power to do so was first known, and the opinions published are almost as numerous as the investigators; the greater part of which having been already collected and published by Professor Faraday in his Fifth Series of Researches, need not be repeated here. Suffice it to say, that the whole of these theories being based upon the supposition that there is a mutual transfer of both the negative and positive elements of an electrolyte, and that supposition being now found incorrect, these theories cease to be tenable.

From the first time that I observed that the base of an electrolyte was not transferred, my mind became impressed with Phil. Mag. S. 3. Vol. 29. No. 192. August 1846. 
\& theory of electrolytic action, which seemed to agree with the results of my every-day experience in electro-metallurgy, and also with various experiments made on a small scale, in order to test these views more fully. During these trials I was favoured with a copy of the paper of the late Professor Daniell and Professor Miller on the decomposition of secondary compounds, in which the non-transfer of the basic element is observed, but the statement made at the same time that this is not universal, some elements, such as potassium, sodium, \&c., being transferred in certain proportions. These statements interfering with my views, induced me to investigate the subject more closely. The paper now submitted to the Society forms a portion of these investigations, the results of which induce me to think it probable that the results obtained by these gentlemen were due to what I term unmeasurable endosmose rather than to electrolytic transfer; and that no basic element of an electrolyte is ever transferred by electrolytic action, but that the base of an electrolyte which is being decomposed is the medium ar conductor of the electricity through the solution from electrode to electrode. And the manner in which this takes place I conceive to be as follows :-

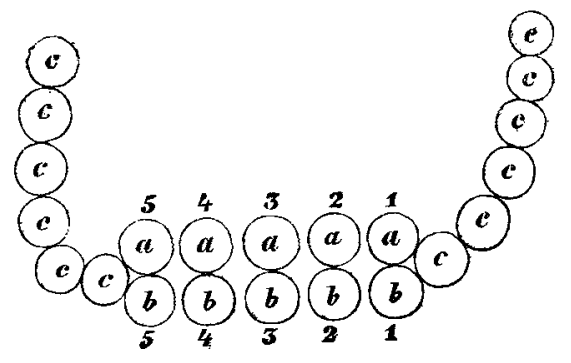

The double row represents a line of compound atoms forming an electrolyte, $a$ the acid or negative element of the electrolyte, $b$ the base or positive element of the electrolyte, $c c$ the wires or solid conductors of the electricity from the battery to the decomposition cell; the last particles in contact with the electrolyte may be viewed as the electrodes. The $a b$ particles are held together by their affinity for each other.

Now let it be supposed that an equivalent of electricity leaves the positive terminal of the battery and passes along the solid particles of the conductor, that particle upon which the electricity rests must be for the time in a higher state of excitement than the other particles. When the electric current comes to the last particle of the solid chain which is in contact 
with the electrolyte, its increased excitement causes it to attract and combine with the acid particle nearest it, $a 1$; when these unite the electricity passes to the first basic particle $b 1$, giving it an exalted excitement, which causes it to unite with the acid particle $a 2$, the electric force passing to $b 2$, which becomes excited in turn and takes the particle $a 3$; and so on through the chain till the last particle $b 5$, which, having no further acid to combine with, gives its electricity to the solid conductor which passes along to the battery. If the last particle $b 5$ be a metal that can exist under the circumstances in which it is left, such as copper, silver, \&c., it accumulates upon that electrode as a deposit; if not such as can exist under these circumstances, such as potassium, \&c., it decomposes water and hydrogen is evolved. By this we observe that every equivalent of decomposition will carry an equivalent of acid to the positive electrode. This is exactly what is found by experiment to be the case. That these decompositions and combinations amongst the particles of a salt may produce a current of that salt in the direction of the electric current producing endosmose, can very easily be conceived.

Whether this be the true philosophy of electrolytic action is yet to be further investigated; in the mean time it does not appear inconsistent with any experiments $I$ have yet investigated : but should it be found not to account for electrolytic action under all circumstances, it will be gratifying should it only prove a stepping-stone to a clearer view of the subtile action of this power.

It appears to me that the phænomena observed and described in these papers favour the idea that electricity is but one power or substance, and that that power is identical with chemical affinity. But the further consideration of this point must be deferred till another opportunity.

XVIII. On a convenient Instrument for graduating Glass Tubes, invented by Prof. Bunsen of Marburg*.

TTHIS instrument consists of a mahogany board $5 \frac{1}{2}$ feet long, 7 inches wide, three-quarters of an inch thick. Throughout its centre is a groove 1 inch wide, half an inch deep, arched at bottom, for the reception of tubes. At one part, 5 inches from the end, is placed a brass plate, $1 \frac{1}{5}$ foot long and 2 inches wide, in such a position that when screwed down its edge comes one-half over the groove. It is furnished

* Communicated by the Chemical Society; having been described by Dr. Lyou Playfair January 19, 1846. 